mediastudies.press • Social Media \& the Self: An Open Reader

\title{
TikTok Face
}

\author{
Cat Zhang
}

Published on: Feb 08, 2021

DOI: $10.32376 / 3 f 8575 c b .5 d e 66 d e 2$

License: Copyright $\odot$ All rights reserved. (COPYRIGHT) 
THE MOST “LIKED” TikTok in 2020 was not some astonishing clip of a goose twerking, girl Renegading, or group of strangers harmonizing the shit out of a sea shanty. It was a deceptively simple recording of a young woman bobbing her head, bouncing between animated expressions as if trying to hypnotize a baby. "It's $\mathrm{M}$ to the B, it's M to the B," she lip-syncs, mouthing the words to a 2016 British diss track. Her cutesy gestures are amplified by TikTok's “Face Zoom” lens, which keeps the camera locked tightly on her expression at all times. At one moment, she smirks peacefully, her eyes relaxed; a few seconds later, she looks moony and cross-eyed, her smile skewed quirkily to the side. In the eyes of her many critics, she is doing nothing-and yet, the "M to the B" TikTok has over 45 million likes, a number greater than the entire population of California.

The young woman is 23-year-old Filipina influencer Bella Poarch, a former U.S. Navy veteran whose emphatically "adorable" facial choreography has made her TikTok's fourth most-followed personality. Her videos' chief draw is that they're "oddly satisfying" - an epithet commonly reserved for ASMR soap-cutting videos, or images of perfectly smooth scoops of peanut butter. These are seemingly ordinary things that nonetheless generate intense visual pleasure; they gratify basic desires for symmetry, repetition and flow. Like ASMR content, Poarch's smooth head-bobbing and elastic gestures lull you into a state of calm. Nothing distracts you from her expressions: Her skin is spotless, her make-up neutral, her background wholly nondescript. Her TikToks are almost too seamless; strangers marvel that she looks "like a Pixar character" in the comments.

Poarch is not the only TikTok creator who's known for her perky facial expressions. Months before Poarch became famous, the 20-year-old Addison Rae, arguably the app's highest paid personality, had shared multiple "Face Zoom" videos of her pouting, crossing her eyes, and grinning to a squeaky beat as part of a "funny faces" challenge. Creators like Angry Reactions or "Kombucha Girl" - who went viral for her wildlyvarying reactions to the fermented drink-have built massive followings for their dramatic affect. Even when one's countenance isn't technically the focus of a video, it is: When asked what makes a good TikTok dance last year, the app's most popular influencer, 16-year-old Charli D’ Amelio, instantly replied, "facial expressions."

On a rudimentary level, it's not too surprising that facial expressions are social currency on TikTok. Humans are naturally drawn to faces, and the rise of photo-centric platforms like Snapchat and Instagram-both of which have invested in their own 
TikTok knockoffs-have accustomed us to documenting and flaunting them. TikTok's animated mannerisms exist within a long lineage of social media looks: In 2009, an Urban Dictionary user identified "duckface" as a "sad and tragic epidemic" infecting female Myspace and Facebook users. The selfie pose accentuates the cheekbones and plumps the lips, pushing one's face closer to the female beauty standard; in its ubiquity, it signaled that a woman was trying "too hard," too unoriginally, to be flirty. A decade later, New Yorker writer Jia Tolentino explored how plastic surgery, filters, and the commodification of personal identity contribute to a "single, cyborgian" "Instagram Face." If posing is trying too hard, then Instagram Face resolves the issue by permanently broadcasting the same cool visage: As Tolentino wrote, "it looks at you coyly but blankly, as if its owner has taken half a Klonopin and is considering asking you for a private-jet ride to Coachella."

TikTok, the most downloaded app in 2020, is a synthesis of many platforms. It has the wittiness and speed of Twitter, the aspirationalism of Instagram, and the communicative intimacy of Snapchat-all of which shape its expressive culture. In late November, Vox reporter Rebecca Jennings identified a collection of "Gen-Z facial tic[s]" she classified as "TikTok Face." Examples include shielding your face with your hand, like you're a celebrity evading interrogation by the paparazzi, or slapping your palm over your mouth in exaggerated shock. One prominent expression comes from the 2012 Disney Channel movie Radio Rebel, in which a shy high school student-played by the actress Debbie Ryan-moonlights secretly as Seattle's most popular radio DJ. Ryan attempts a coy, guileless smirk: she brushes her bangs from her face, her face cast downward, looking up as if to ask, "who, me?" On TikTok, bashfully tucking your hair like Ryan became an ironic gesture, a parody of artificial modesty.

On Twitter, where semantic cleverness takes priority over personal appearance, the Debbie Ryan face would have simply circulated as the original gif from Radio Rebel. TikTok, on the other hand, is designed specifically for casual self-recordings and visual riffs. The app allows videos to occupy the whole screen instead of cropping them awkwardly, and funnels user content into one continuous stream, maximizing ease of consumption. Like a Twitter-friendly reaction gif, “TikTok Face” centers on a narrow movement that is visually gratifying and becomes humorous through repetition; but because TikTok is about putting your own personalized spin on a challenge, individual TikTok creators recreated the Debby Ryan smirk themselves instead of circulating preexisting clips, incorporating it into daily_rants and throwaway memes. Their reaction is embodied, making it more personal: the attraction is not just the meme itself, but the 
addition of "pure" personality, enabling viewers to imagine what creators might be like off screen.

The ease with which "TikTok Face" is deployed evokes the intimacy of Snapchat, where teenagers trade mundane selfies of themselves doing nothing. Often, the content of a snap matters less than merely getting one; sending daily pictures of your face to your friends, and vice versa, establishes a baseline closeness and loyalty. TikTok opens this private dynamic up to the masses: Even if I'm merely watching Charli D'Amelio smile and suck in her cheeks, I am still comforted by the routine of seeing her face appear on my feed. The 16-year-old may star in Superbowl commercials and appear on Fallon, but her wide grins, puckered lips, and sideways tongues project goofiness and normality. Some personalities can even "coin" their own facial expressionsAddison Rae is known for her signature nose scrunch, which is meant to convey a cute, silly image favored by younger audiences. And yet, faces are subject to alternative meanings: Through mocking imitation, the scrunch has become a signifier for the beautiful, basic white girl-a criticism of her privilege, perceived dim-wittedness, and artificiality.

While TikTok Face can be inane, even unattractive, its most cherished practitioners are conventionally pretty. They are thin, light-skinned and feminine; they also film themselves with high-resolution smartphone cameras and near-professional lighting. Much of this is by design: "If the character's appearance or the shooting environment is not good, the video will be much less attractive," reads an early TikTok guide, encouraging moderators to suppress posts from the poor, disabled and "ugly" to retain new users. But in contrast to Instagram, where visual attractiveness also reigns, TikTok values girl-next-door relatability over modelesque sexiness-in part, perhaps, because of the app's younger user base. For example, while Instagram gurus might sweep blush diagonally along the cheekbones to sculpt and sharpen their face, TikTok stars typically apply blush horizontally across the nose for a softer "e-girl" look, sometimes even adding freckles. Emulating this make-up style in a Vogue YouTube tutorial, the pop star Doja Cat described it as a "sickly look where I look like I just woke up, blew my nose and I have pneumonia." It cultivates an aura of innocence and vulnerability. (The act can go too far: Bella Poarch-who projects a childlike preciousness in her videos, including wearing her blush across her nose-has been accused of acting so far below her age that she caters to pedophiles.)

Ultimately, TikTok's most unique feature is its algorithm, which could fling your content onto any stranger's feed, instead of restricting it to those who follow you. This 
arbitrariness, the inability to anticipate your audience, may incentivize creators to cater to the lowest common denominator. Poarch's goal, it seems, is to abstract her face into something as blank and universally appealing as the iconic yellow smiley. In her book Theory of the Gimmick, the cultural and literary critic Sianne Ngai argues that the seemingly-innocuous smiley expresses "the face of no one in particular," embodying "an uncanny personification of the collectively achieved abstractions of the capitalist economy." Invented to boost morale at an insurance company, the icon transcends language and context, seemingly including everybody but also becoming creepy, even oppressive, in its all-inclusivity. Similarly, Poarch's facial choreography is sanitized of almost all particularity: There is no storyline, so it is legible across all genders, ages, and ethnicities. In fact, in several TikToks, she imitates emojis lined up on the top of the screen- "Angry Face," "Zany Face," "Face with Tears of Joy"stripping all else from the frame with her usual "Face Zoom" filter. "I think you are definitely being held captive by TikTok," one person wrote on her original "M to the B" video.

The notion that Poarch is being "held captive"-maintaining an outward display of normalcy while masking darker, actual feelings-recalls the work of sociologist Arlie Hochschild, who in the 1980s developed the concept of "emotional labor" to describe how certain workers must regulate their emotions in order to fulfill the requirements of their jobs. A duty of flight attendants is to provide a pleasant experience for passengers, so they must smile constantly, as though producing cheerfulness is a service similar to in-flight snacks and cocktails. Their smiles do not "belong" to themthey are simply mobilizing the requisite warmth to get through the job.

TikTok, with its emphasis on short, entrancing content, makes this estrangement the focus of the viewing experience. This is implicit in the praise of Bella Poarch's facial movements as "oddly satisfying": the subtle implication is that her face is a raw material, like slime or soap, manipulable for her audience's aesthetic pleasure. She has built a career, including brand deals, off of this emoji-fication, the ability to immediately signal an emotion without feeling it, reducing oneself to a logo. TikTok users have learned to crowdsource for money by asking strangers to interact with their videos, in the hopes of getting payout from TikTok's creator fund. Perhaps this is par for the course for our 21st-century attention economy. When broadcast online, almost all ordinary activities can become a monetizable form of labor: eating (mukbang), asking about one's day (ASMR boyfriends), and popping zits (self-explanatory). Why not sell the most elemental aspect of human communication: smiling. 
Cat Zhang is a writer based in Brooklyn. She is on staff at Pitchfork, where she writes a column dissecting the musical trends of TikTok.

\section{REPRINT}

“TikTok Face” (Cat Zhang, Real Life, February 8, 2021)

REPRINTED WITH PERMISSION FROM REAL LIFE, WHICH RESERVES ALL RIGHTS 